\title{
Augmented Reality as Learning Medium for Preservation of Traditional Musical Instruments in Bangka
}

\author{
Fransiskus Panca Juniawan'1), Dwi Yuny Sylfania2) \\ Information Technology Study Program \\ STMIK Atma Luhur, Jl. Jendral Sudirman, Pangkalpinang1,2) \\ Email: fransiskus.pj@atmaluhur.ac.id ${ }^{1)}$, dysylfania@atmaluhur.ac.id ${ }^{2)}$
}

Received September 16, 2019; Revised November 27, 2019; Accepted December 5, 2019

\begin{abstract}
Nowadays the use of technology is something that can be found anywhere. This condition has an impact on the loss of awareness of the Indonesian cultural treasures value in the form of traditional tools. No exception to traditional musical instruments on Bangka Island which began to lose its popularity. At present, most teenagers on Bangka Island cannot play traditional musical instruments. Likewise with the children who do not know and not even know their own regional musical instruments. With the continuation of this condition, it is feared that the existence of traditional Bangka musical instruments will disappear, as well as human resources that can play it. Augmented Reality (AR) is a visual technology that can display objects in 3D. The advantage of this technology is being able to give a display of real-time musical instrument in the form of dynamic 3D visualization of objects and it is in accordance with the movements of the user's smartphone camera. AR has also been applied in various cases as a solution to problem-solving. Therefore, to overcome this problem, an application to preserve the traditional Bangka musical instruments using Augmented Reality (AR) is proposed. This research uses a marker-based AR method because of its high position accuracy. The 3D objects of musical instruments are made using Maya. Unity is also used as an engine for the application of 3D modeling on the Android system, and Vuforia SDK as it's augmented reality engine. The results of performance testing obtained $100 \%$ running well. From the results of testing the user experience with the HARUS method, it is proven that the system has comprehensibility aspects of $75.98 \%$ and manipulability aspects of $80.74 \%$ so that the total value HARUS be $78.36 \%$.
\end{abstract}

Keywords: Augmented Reality, Preservation, Traditional Musical Instrument, HARUS Score. 


\section{INTRODUCTION}

Bangka Island is an island in Indonesia that is rich in diversity of tradition and traditional culture. One of them is the number of traditional musical instruments in Bangka. There are many traditional musical instruments in Bangka, including Dambus, Rebab, Rebanatamborin, Gong, Suling Bangka, Gendang Melayu, Gambangan, and Caklemong. Every musical instrument has its own unique and distinctive features.

Currently, the use of technology by children and teenagers is a common thing that we can find anywhere. However, the bad impact is their ability to build social relations are going to reduced, low social care, and low knowledge of the tradition and traditional culture in their area. Specifically at the last point, it has an impact on the ability to use traditional Bangka musical instruments. This is a common concern if the next generation of Bangka island do not know and cannot play the traditional musical instruments. At present, most teenagers in Bangka cannot play traditional musical instruments. Likewise, with children, they do not know yet and do not even know their own regional musical instruments. If this condition continues, it is feared that the existence of traditional Bangka musical instruments will disappear, as well as human resources that can play it.

To overcome the problems that have been formulated, a system is proposed that has a function as a medium that can introduce traditional Bangka musical instruments to early childhood. The system is built using a technology that is familiar to children, namely Augmented Reality (AR). Augmented Reality (AR) is a visual technology that can describe objects in 3D and can be used on any mobile smartphones. The advantage is the ease of building process and its development. AR has been applied in various cases as a solution to any problem.

This technology (AR) is relatively easier to use by children's user because it is interesting and interactive. This research uses AR with a marker-based method because it is easier to use by children. In addition, it does not require additional devices, only requires a paper that is relatively cheap as a media marker [1]. Another reason is because marker-based has a very high position accuracy for it's 3D objects [2]. Viewed from the other side, Augmented Reality is able to display 3D objects in real time so that users can observe objects in detail. Vuforia and Unity Game Engine is used to build AR so that it can be applied to smartphones with the Android operating system.

\section{RELATED WORKS}

Research that has been done before is the implementation of AR to the education system for children with special needs. By using AR technology, it attracts children's interest and attention more than conventional teaching methods. The research results obtained an opinion according to psychoeducators that AR is a technology that can be used by anyone and can be used to increase the level of activation of the teaching process to students [3]. Also conducted research on the reasons why many people play games based on 
Mobile Location on AR. For example, Pokemon Go which is widely played. There are many benefits for users, but there are also disadvantages. First is the problem of user privacy and poor usability. This study investigated several game users and also studied the links between gratification and user intentions to continue playing, and also to spend money. The research results are aspects of play comfort, outdoor activities, ease of use, challenges, and nostalgia are positively related to Intentions to Reuse (ITR). It is also connected directly with in-app purchase intentions (IPI). Privacy and trendline issues are not connected with IPI [4]. AR made using gyroscope functions and did not use markers to demonstrate the position of the Goddess Nawa Sanga by the Hindu community in Bali. From the results of the questionnaire distributed, the value of application functionality was obtained at $88.4 \%$ and the value of the ease of use and satisfaction was $84.8 \%$ [5]. AR can also be applied to the field of design, namely an interactive teaching system for mechanical drawing courses. The results of the demonstration show that the course class that uses AR media is superior to the course class with conventional drawing tools. This is based on the key criteria of the course, the level of difficulty in the content area, the ability of spatial imagination, and the level of interest in learning after class [6]. Learning Thai students about the human heart is also made using AR. This study aims to explore bilingual namely Thai and English. AR was evaluated by 5 experts based on the Index of Item Objective Congruence (IOC), Diffusion of Innovation (DOI), and Content Validity Index (CVI). The results of learning before AR have been analyzed with $\mathrm{P}<0.001$ with $\mathrm{T}$-Test. The effectiveness of the application is evaluated by the user based on the theory of Unified Theory Acceptance and Use of Technology (UTAUT). The arithmetic mean and standard deviation are valued at 4.65 and 0.48 [7]. Furthermore, AR is applied to a model based on visual communication-based networks. The results of the study found that the application that was built provided a new model in teaching and enriched the content of the class taught. In addition, this application increases the level of participation and enthusiasm of students, and also increases the effect of teaching [8]. Furthermore, there are studies that study the effects of the use of AR on student learning motivation. Attention, Relevance, Confidence, and Satisfaction (ARCS) models are used to measure the impact of their use. From a total of 78 respondents who filled out the questionnaire, it was found that factors of attention, satisfaction, and confidence are increased significantly with the use of AR applications [9].

AR-based Digital Learning Object (DLO) planning and allocation use the VARK Model for higher education students. The results of this study prove that it has an important impact on teaching activities in the planning phase. In addition, DLO with AR can be reused as a characteristic, this can be used whenever students need it and in the same way, can facilitate their learning process [10]. Research is conducted to determine the advantages and potential of using AR for communication at presentations. The system built allows the speaker to use an AR-based Head-Mounted Display to display 
visually on the speaker's head. The results of the study are that the system is able to help the speaker to understand the content and explain it to listeners, and is also able to regulate listener intervention and improve the flow of presentations [11]. AR is also applied as a cultural display and history of buildings in Thailand for tourists (ARCH-Tour). Testing is done by asking for a response from tourists. The system is built attractively and has useful information. However, the use of low camera quality affects the process of capture and 3D visualization of building models. Light quality also influences the marker reading process [12]. AR-based tourist souvenirs are also made that can display monument information and display 360 degrees. The marker system is applied in the form of a postcard [13]. Developed applications from interactive objects for AR using Oculus Rift, Leap Motion Controller (LMC) and cameras. Prepared an AR-based video display to work on the AR book. The LMC application can increase interactive value with different hand gestures like thumb up, down and pinching. The result is an increase in user experience in interacting, engaging, and responding to the information [14]. $\mathrm{AR}$ is also used as a simulation media for earthquakes for people who are in the tower. This was done to increase knowledge about the risk of the earthquake. By displaying 3D graphics, users can experience the level of damage to buildings and maintain a safe distance. With the presence of AR, users become aware of the risk of earthquakes in buildings [15].

From the elaboration of previous research, it can be concluded that AR can be applied in various cases. By using marker-based AR, the research conducted tries to provide choices for children to learn traditional music instruments. The system built then measured the quality of the system using the HARUS method so that the quality of the system being built is known.

\section{METHOD}

This research consists of 4 steps, namely data collection, 3D modeling design, build the AR marker, and testing and implementation. The four steps are described in Figure 1 as below.

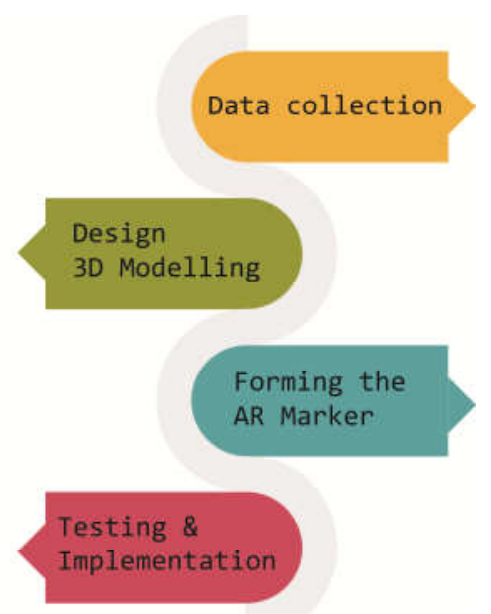

Figure 1. Stage of Research 


\subsection{Data Collection}

Raw data on traditional Bangka musical instruments were collected from various sources, including literature studies, interviews of traditional elders and interviews with Western Bangka art experts. The final results are valid data on traditional musical instruments along with its images.

\subsection{Design 3D Modelling}

After the data was obtained, the design of traditional musical instruments in 3D format was made. The design is made using the Maya 3D Modeling tool. Maya was chosen because its superiority has good performance, ease of use, and high physical flexibility [16].

\subsection{AR Marker}

To make a marker, this study uses the online-based Vuforia SDK tool. Vuforia SDK is used to make markers to be converted into AR plugins [13]. Markers are made using the Marker-Based Tracking method [17] and use 3D images of each musical instrument that have made. The Marker-Based method architecture is described in Figure 2.

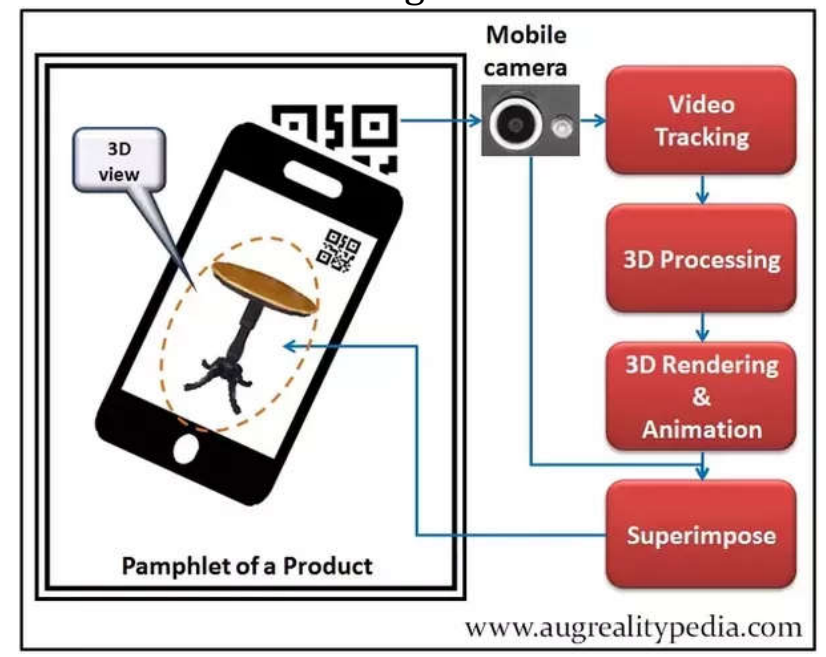

Figure 2. AR marker-based architecture [17]

\subsection{Testing and Implementation}

After the marker was made then imported to Unity so that it can be combined with 3D objects of musical instruments. In Unity interface settings and intense functions can be performed on the Android application. This study uses a questionnaire survey as a method of testing the feasibility of using the application. Respondents were randomly selected with a total of 53 students from several elementary schools in the City of Pangkalpinang. Distribution of questionnaires directly by going to school and asking for time to experience using the system that was built. A total of 22 children (41.5\%) were women and 31 men (58.5\%). The average age of a child is 7.9 from 5 elementary schools. The survey is conducted on 5 November 2018 until 27 January 2019. Besides that, it also uses the approaching model HARUS (Handheld Augmented Reality Usability Scale) which is used to determine the possible problems of use [18]. 


\section{EXPERIMENT RESULT}

This research introduces 4 traditional Bangka musical instruments, namely Dambus, Gong, Rebab, and Rebana. The process of making the system consists of the following steps:

\subsection{D Modelling}

Created the fourth 3D model of musical tools based on photos that have been obtained at the data collection stage. The four musical instruments are designed using Maya's 3D modeling tool. In Figure 3 shows the results of making models of traditional Bangka musical instruments. After completion, the model is saved in the .obj format so that it can be recognized by Unity as the AR engine.

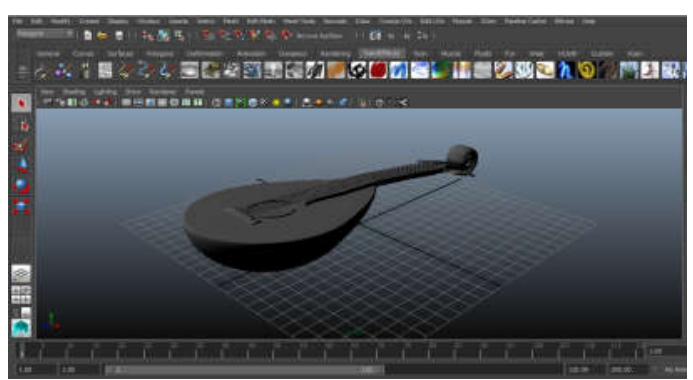

(a)

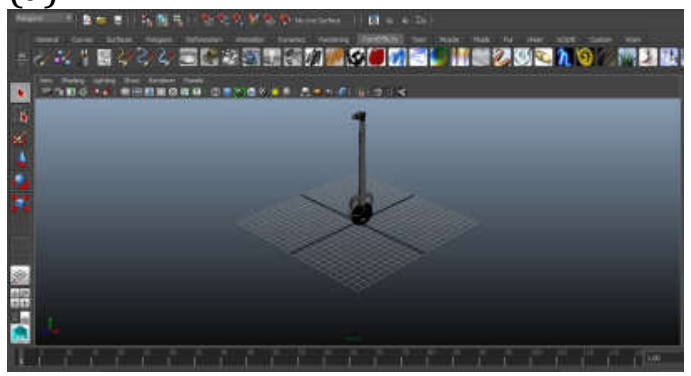

(c)

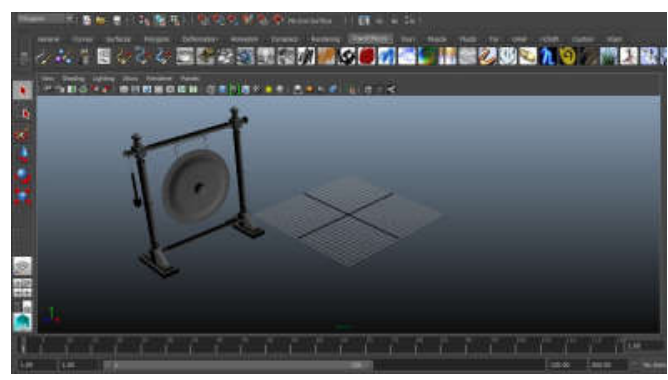

(b)

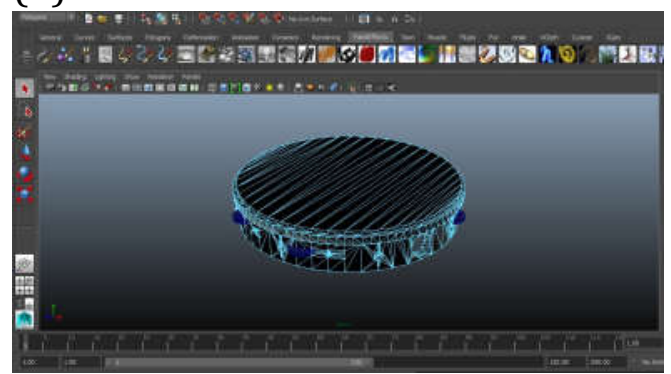

(d)

Figure 3. 3D Modelling in Maya. (a) Dambus, (b) Gong, (c) Rebab, (d)

Rebanatamborin

\subsection{Marker-Based Using Vuforia SDK}

To create AR markers, use the online Vuforia SDK tool. Images that have been determined as markers are uploaded and processed into markers online. Marker images that have been completed processed as markers are then downloaded so it can be combined into Unity. The process of making markers can be seen in Figure 4. 


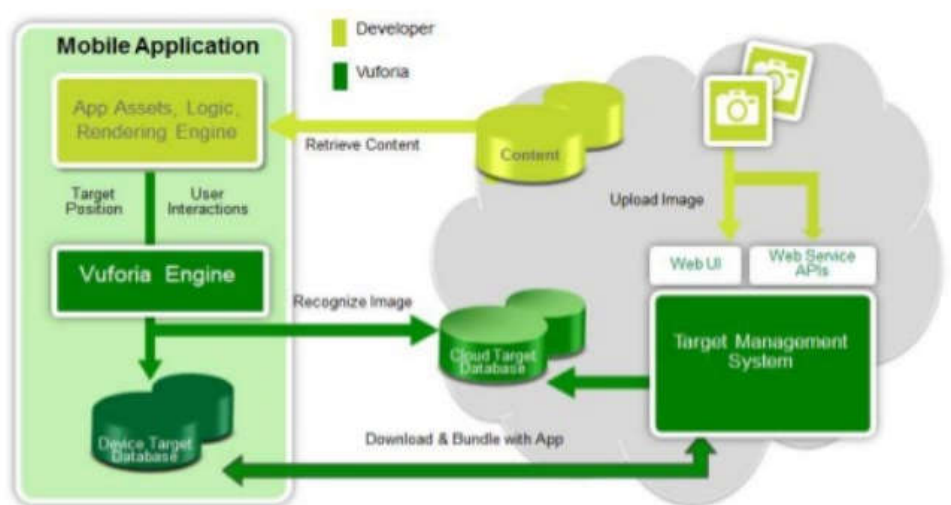

Figure 4. Marker Building Process in Vuforia SDK

Whereas the Vuforia SDK architecture is explained in Figure 5.

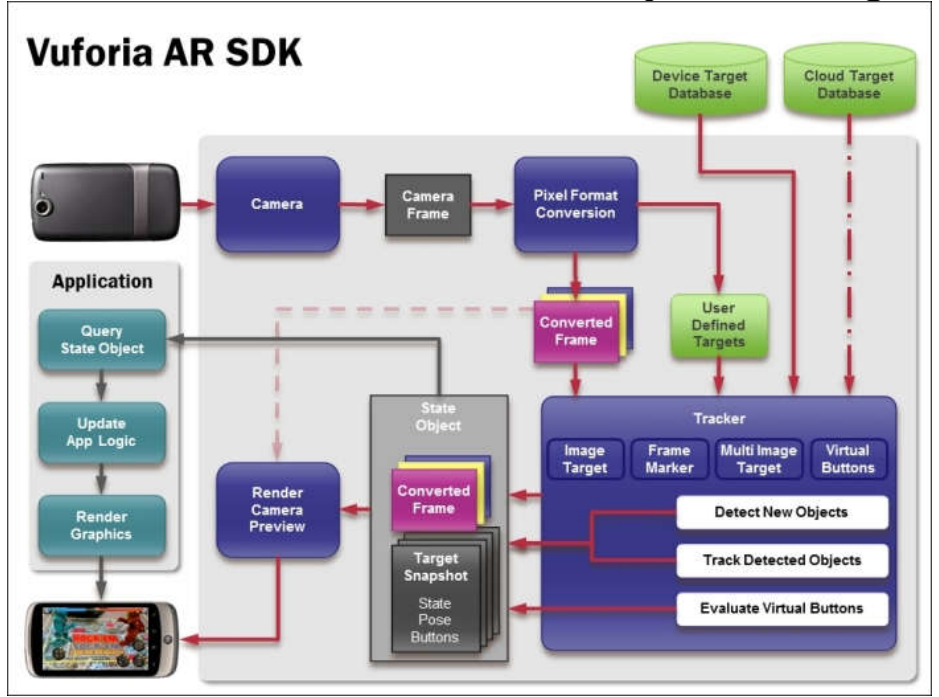

Figure 5. Vuforia SDK Architecture

\subsection{System Interface}

Because this research is intended for users in early childhood, the application interface also plays an important role. The interface is made in Unity by paying attention to aspects that can attract children's attention and interest. The interface can be seen in Figure 6.

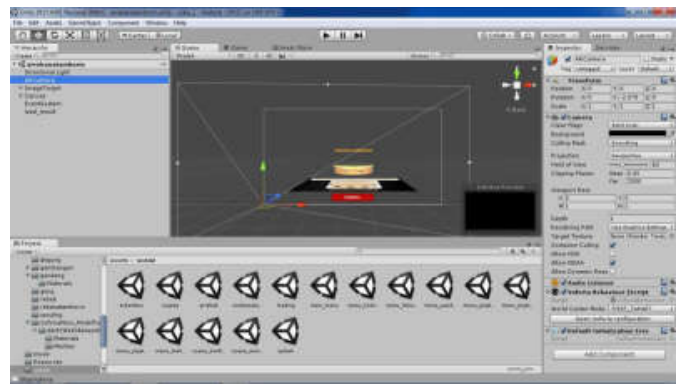

(a)

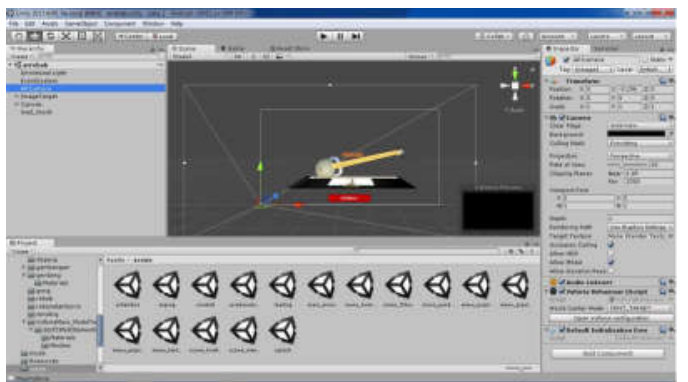

(b)

Figure 6. 3D object interface in Unity (a) Rebanatamborin, (b) Rebab 


\subsection{AR Implementation}

Figure 7 shows the AR displays of each musical instrument object on the marker that was made in Vuforia. The display is obtained using a smartphone with the following specifications:

- Processor Qualcomm SDM845 Snapdragon 845

- ROM 6 GB

- GPU Adreno 630

- Memory $64 \mathrm{~GB}$

Camera 12 MP, f/1.9, 1/2.55", 1.4 $\mathrm{m}$, dual pixel PDAF and $5 \mathrm{MP}, \mathrm{f} / 2.0$, $1.12 \mu \mathrm{m}$, depth sensor

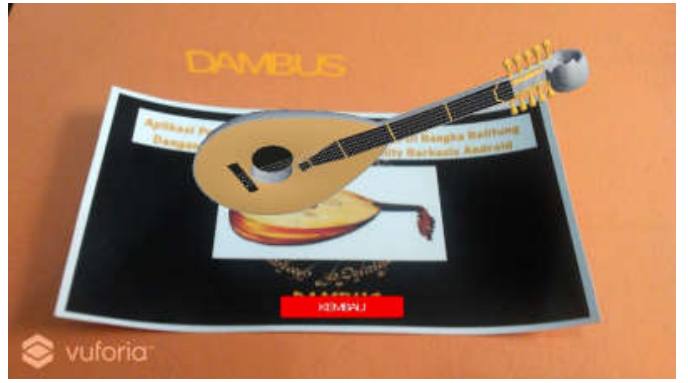

(a)

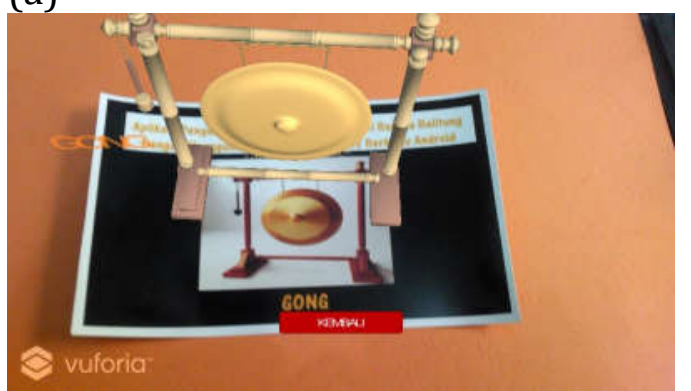

(c)

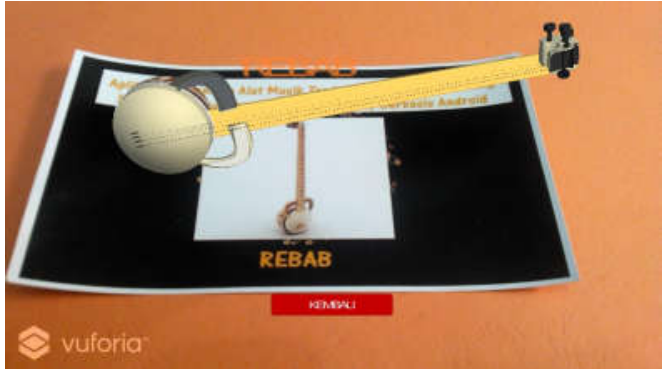

(b)

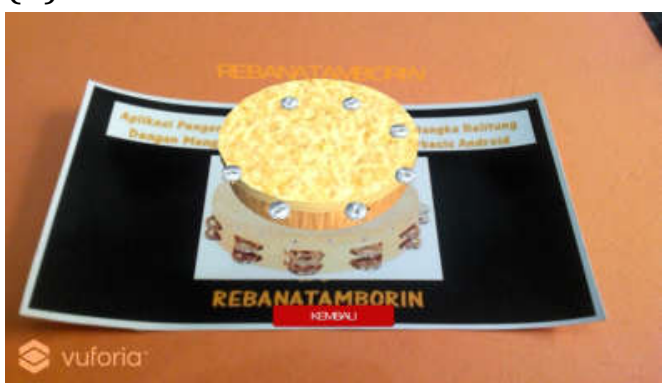

(d)

Figure 7. 3D object interface in Unity (a) Rebanatamborin, (b) Rebab

\section{ANALYSIS}

\subsection{Performance Marker Testing}

Performance testing is explained in Figure 8 which tests the performance of markers that have been made. The test are using the Blackbox method that focuses to determine the reading results of markers when the camera captures more than one marker. The test is carried out in indoor location with sufficient bright light conditions. From the test results, obtained that the system can display 3D objects according to the menu chosen by the user properly. The system does not display objects other than the menu chosen by the user, even though all four markers are within the range of the camera. This test aims to determine the validation and performance of markers according to the object menu of the selected musical instrument, so that users do not experience confusion when viewing 3D results. 
In Figure 8a, the Rebanatamborin menu is selected and the result that appears is a 3D Rebanatamborin object. In Figure 8b, the Rebab menu is selected and the result show is the Rebab object.

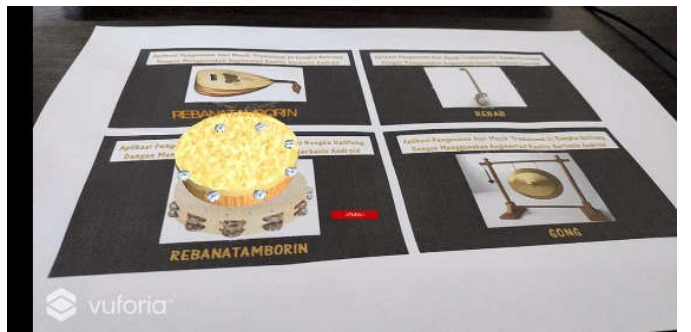

(a)

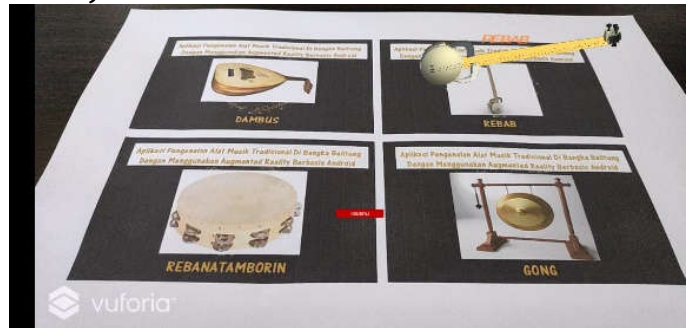

(b)

Figure 8. Marker Testing (a) Rebanatamborin, (b) Rebab

\subsection{Experience User Testing Using HARUS (Handheld Augmented Reality Usability Scale)}

For testing user experience, a questionnaire is distributed using the HARUS (Handheld Augmented Reality Usability Scale) method. This method was chosen because it can aggregate usability, comprehensibility, and manipulability into single scores [18]. This method is divided into 2 stages, namely the formation of a HAR issue questionnaire, then the formation of a sub-questionnaire HARUS. The first stage was making questionnaires in accordance with the issues on HAR (Handheld Augmented Reality) with the stages of designing a questionnaire based on the background of the HAR, then conceptualizing the questionnaire, determining the format and analysis of data. Then in the second stage. we add the sub-questionnaire HARUS to determine the comprehensibility and manipulability scale. HARUS method consists of 16 statements divided into two aspects, namely comprehensibility and manipulability described in Table 1.

Table 1. HARUS Questions [19]

\begin{tabular}{|c|c|}
\hline \multicolumn{2}{|r|}{ Comprehensibility } \\
\hline 1 & $\begin{array}{c}\text { I think that interacting with this application requires a lot of mental } \\
\text { effort. }\end{array}$ \\
\hline 2 & $\begin{array}{c}\text { I thought the amount of information displayed on the screen was } \\
\text { appropriate. }\end{array}$ \\
\hline 3 & $\begin{array}{c}\text { I thought that the information displayed on the screen was difficult to } \\
\text { read. }\end{array}$ \\
\hline 4 & I felt that the information display was responding fast enough. \\
\hline 5 & I thought that the information displayed on the screen was confusing. \\
\hline 6 & I thought the words and symbols on the screen were easy to read. \\
\hline 7 & I felt that the display was flickering too much. \\
\hline 8 & I thought that the information displayed on the screen was consistent. \\
\hline \multicolumn{2}{|r|}{ Manipulability } \\
\hline 9 & $\begin{array}{l}\text { I think that interacting with this application requires a lot of body } \\
\text { muscle effort. }\end{array}$ \\
\hline 10 & I felt that using the application was comfortable for my arms and hands. \\
\hline
\end{tabular}




\begin{tabular}{|c|c|}
\hline \multicolumn{2}{|c|}{ Comprehensibility } \\
\hline 11 & I found the device difficult to hold while operating the application. \\
\hline 12 & I found it easy to input information through the application. \\
\hline 13 & I felt that my arm or hand became tired after using the application. \\
\hline 14 & I think the application is easy to control. \\
\hline 15 & I felt that I was losing grip and dropping the device at some point. \\
\hline 16 & I think the operation of this application is simple and uncomplicated. \\
\hline
\end{tabular}

1) HARUS Calculation

HARUS Calculation is equated with SUS [20]. The 1-7 Likert scale is used to determine the level of the user agreement, with 1 meaning "Strongly Disagree" and 7 means "Strongly Agree". To get HARUS value, the first step is to convert the respondent's assessment results to a range of 0-6. The trick is for statements with positive responses we subtract one from the response given by the user, while for negative statements we do a reduction of seven minus the value of the user response. The second step is to add the results of this conversion so that you get a maximum of 96 points. This is because the total statement is 16 , while the maximum conversion value obtained is 6 , then we multiply $16 * 6=96$. The third step is to divide the results in the second stage with 0.96 to get values in the range 0-100 [19].

2) HARUS Testing Result

From 53 respondents who were given questionnaires using the HARUS assessment method, the results for comprehensibility and manipulability aspects can be seen in Figure 9, and total HARUS score in Figure 10.

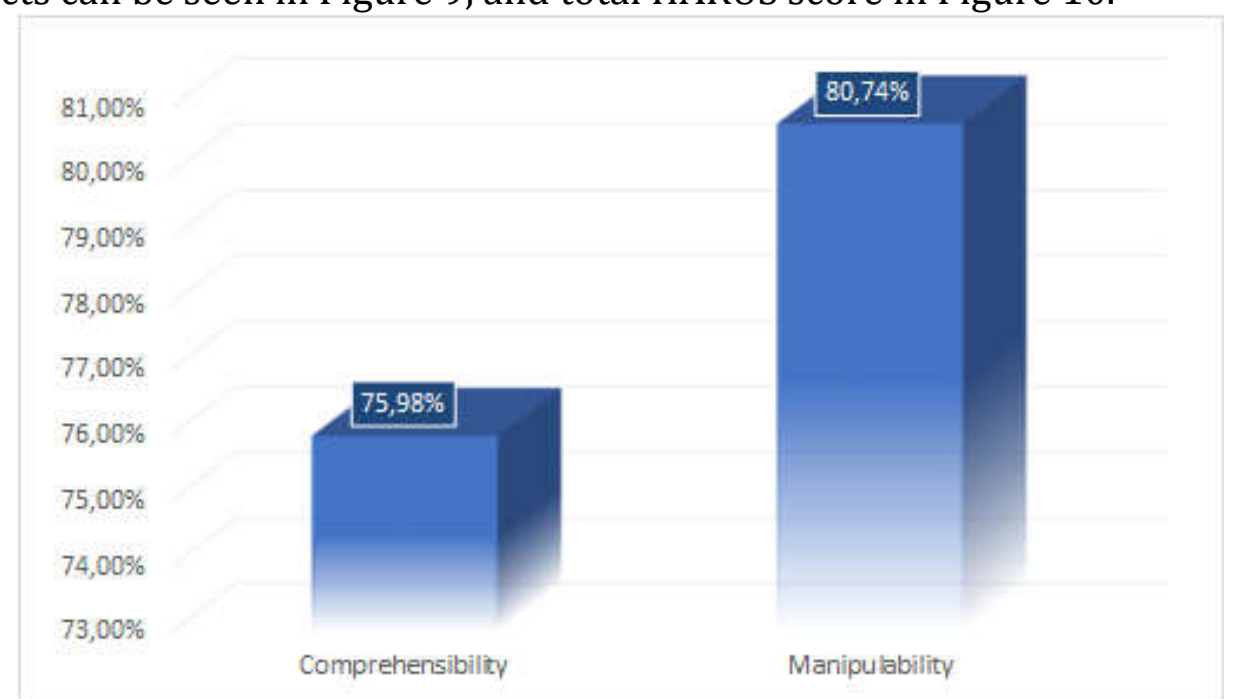

Figure 9. Comprehensibility and Manipulability aspect in HARUS 


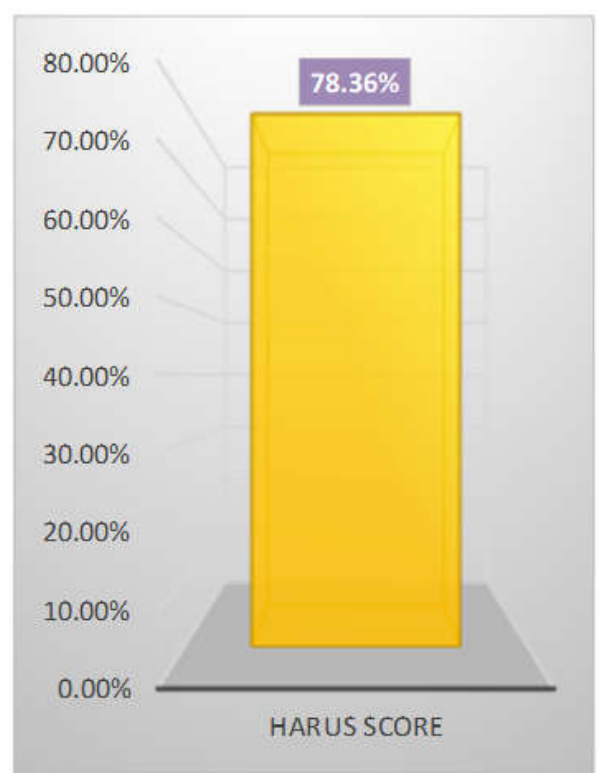

Figure 10. Overall HARUS score testing

Traditional musical instruments are cultures that must be preserved. The solution in the form of preservation in Augmented Reality learning media. The system built displays four traditional musical instruments, namely Dambus, Rebab, Rebanatamborin, and Gong. The system was built using Unity, Vuforia SDK, and Maya. The performance of the system has reaches $100 \%$. This is evidenced by the marker testing that proves that the system can recognize its marker appropriate with the menu that user's choose. Another testing is based on user experience using the HARUS (Handheld Augmented Reality Usability Scale) valuation method. The survey was distributed to 53 students from several elementary schools in Pangkalpinang City. With an average age of 7.9 years. From the test, the results for the Comprehensibility aspect were $75.98 \%$ and the Manipulability aspect was $80.74 \%$. The combination of the two aspects produces a HARUS value of $78.36 \%$. If it is returned to its scale interval (Likert with 7 statements), the system built is in the "Agree" category with all HARUS statements given.

\section{CONCLUSION}

Augmented Reality (AR) can be applied as a introduction of traditional Bangka musical instruments for the user (kids). The kids can see and learn the shapes of traditional Bangka musical instruments in 3D form. The purpose of implementing AR in this application is to increase the enthusiasm and interest of children in learning the traditional Bangka musical instruments. From the results of testing user experience taken from 53 children and calculated using the Handheld Augmented Reality Usability Scale (HARUS) method, the results for the Comprehensibility value are $75.98 \%$ and for the Manipulability value of $80.74 \%$ were obtained. The 
average of both is $78.36 \%$. This means, that based on the statements proposed in Table 1, all users feel "agree" with all statements.

For further research, the system can add some original sounds of traditional music instruments according to the available objects. In addition, other traditional musical instrument objects can also be added. From the technology side, AR can be built using the markerless method as an option to the user.

\section{Acknowledgements}

We would like to say thank you to STMIK Atma Luhur for funding this research in the program of internal research grant.

\section{REFERENCES}

[1] J. C. Cheng, K. Chen, and W. Chen, Comparison of Marker-based AR and Marker-less AR: A Case Study on Indoor Decoration System, Lean and Computing in Construction Congress (LC3): Proceedings of the Joint Conference on Computing in Construction (JC3), pp. 483-490, 2017.

[2] F. P. Juniawan, D. Y. Sylfania, H. A. Pradana, and Laurentinus, Pengenalan alat musik tradisional Bangka dengan Marker-Based Augmented Reality, Register: Jurnal Ilmiah Teknologi Sistem Informasi, vol. 5, no. 2, pp. 89-105, 2019.

[3] C. Țurcanu, B. M. Prodea, and C. Constantin, The Opportunity of Using Augmented Reality in Educating Disadvantaged Children, Bulletin of the Transilvania University of Brasov. Economic Sciences, vol. 11, no. 1, pp. 71-78, 2018.

[4] J. Hamari, A. Malik, J. Koski, and A. Johri, Uses and Gratifications of Pokémon Go: Why do People Play Mobile Location-Based Augmented Reality Games?, International Journal of Human Computer Interaction, vol. 34, no. 01, pp. 1-16, 2018.

[5] I. W. A. Indrawan, I. P. A. Bayupati, and D. P. Singgih Putri, Markerless Augmented Reality Utilizing Gyroscope to Demonstrate the Position of Dewata Nawa Sanga, International Journal of Interaction Mobile Technology, vol. 12, no. 1, pp. 19-35, 2018.

[6] W. C, Juan, W. T. Dian, W.Y. Lin, S, Construction of Interactive Teaching System for Course of Mechanical Drawing Based on Mobile Augmented Reality Technology State of the art, International Journal of Emerging Technologies in Learning, vol. 13, no. 2, pp. 126139, 2018.

[7] S. Nuanmeesri, The augmented reality for teaching Thai students about the human heart, International Journal of Emerging Technologies in Learning, vol. 13, no. 6, pp. 203-213, 2018.

[8] Y. Zhao and C. Chen, The Application of Augmented Reality in University, International Journal of Emerging Technologies in Learning, vol. 13, no. 7, pp. 57-70, 2017. 
[9] T. Khan, K. Johnston, and J. Ophoff, The Impact of an Augmented Reality Application on Learning Motivation of Students, Advances in Human-Computer Interaction, vol. 2019, no. 1, pp. 1-14, 2019.

[10] M. Medina, C. García, and M. Olguín, Planning and Allocation of Digital Learning Objects with Augmented Reality to Higher Education Students According to the VARK Model, International Journal of Interactive Multimedia and Artificial Intelligence, vol. 5, no. 2, pp. 53-57, 2018.

[11] T. Zarraonandia, I. Aedo, P. Díaz, and A. Montero Montes, Augmented Presentations: Supporting the Communication in Presentations by Means of Augmented Reality, International Journal of Human Computer Interaction, vol. 30, no. 10, pp. 829-838, 2014.

[12] A. Roongrungsi, C. S. Namahoot, and M. Brückner, Augmented reality application for cultural and historical tourist attraction display (ARCH-TOUR), Journal of Telecommunication, Electronic and Computer Engineering, vol. 9, no. 2-4, pp. 65-69, 2017.

[13] L. W. Shang, M. H. Zakaria, and I. Ahmad, Mobile Phone Augmented Reality Postcard, Journal of Telecommunication, Electronic and Computer Engineering, vol. 8, no. 2, pp. 135-139, 2016.

[14] Y. J. Wai and N. B. Abd Manap, Interactive Objects for Augmented Reality by Using Oculus Rift and Motion Sensor, Journal of Telecommunication, Electronic and Computer Engineering, vol. 10, no. 26, pp. 149-153, 2018.

[15] M. U. Pemenang, A. Basuki, and R. Sigit, An Augmented Reality Application for the Community Learning about the Risk of Earthquake in a Multi-storey Building Area, Emitter International of Engineering Technology, vol. 5, no. 2, pp. 192-208, 2017.

[16] Autodesk, The Art of Maya, 4th ed. San Rafael: Autodesk, Inc, 2007.

[17] S. Kumar, 7 Amazing Facts about Augmented Reality: Your Tech World, Augrealitypedia, 2016. [Online]. Available: https://www.augrealitypedia.com/7-amazing-facts-augmented-realitytech/. [Accessed: 18-Mar-2019].

[18] M. E. C. Santos, J. Polvi, T. Taketomi, G. Yamamoto, C. Sandor, and H. Kato, Toward Standard Usability Questionnaires for Handheld Augmented Reality, IEEE Computer Graphic Applied, vol. 35, no. 5, pp. 66-75, 2015.

[19] M. E. C. Santos, T. Taketomi, C. Sandor, J. Polvi, G. Yamamoto, and H. Kato, A usability scale for handheld augmented reality, $A C M$ Symposium on Virtual Reality Software and Technology, pp. 167-176, 2014.

[20] A. Bangor, P. T. Kortum, and J. T. Miller, An empirical evaluation of the system usability scale, International Journal of Human Computer Interaction, vol. 24, no. 6, pp. 574-594, 2008. 